\title{
The informative nature of the tests for evaluating the processability of a steel product
}

\author{
Alla Katanina, Alexander Shuvalov* and Oleg Kornev \\ Moscow State University of Civil Engineering, Yaroslavskoe shosse, 26, Moscow, 129337, Russia
}

\begin{abstract}
The reasons for the appearance of cracks in the mounting connection, which is an unequal angle obtained by a plate at a right angle of $8 \times 210 \times 100$, are investigated. The limited information received at the standard scope of material tests is shown to assess the processability of the product. Investigation of the composition, structure and viscosity of the material made it possible to establish that in order to obtain a quality product from rolled steel of St3sp, it is necessary to make changes in the technological operations of cutting and bending the production of the part. When performing the cutting operation of sheet metal, the long side of the plate $(210 \mathrm{~mm})$ should be placed along the direction of the fibers of the structure. During bending, the edge of the folding of the sheet must be made across the rolled fiber. For steels that are prone to splitting along the fibers of the structure, correct cutting of the sheet will prevent the formation of cracks along the stretched bending surface and fatigue failure during welding and operation of the assembly line.
\end{abstract}

\section{Introduction}

A set of product properties that determine the suitability of its design to achieve optimal cost in production and operation for specified quality indicators is the technological design of the product [1]. In the considered case, the product is an uneven angle obtained by bending a plate at a right angle with dimensions of $8 \times 210 \times 100 \mathrm{~mm}$. It is generally accepted that the ability of a part called "installation link" to perform its basic functions is directly determined by its design performance without regard for its manufacturability. However, on the outer convex bending surface subjected to stretching defects in the form of cracks were found by the consumer in the consignment of the produced products. It is assumed that the discontinuity of the steel plate visible to the naked eye occurred during the technological operation of steel sheet bending.

The purpose of the work is to determine the causes of crack formation and develop recommendations for improving the quality of the product.

\footnotetext{
${ }^{*}$ Corresponding author: edic@mgsu.ru
} 


\section{Practice and literature review}

The resistance to viscous fracture of steel during pressure treatment is determined by the ability of the material to have plastic deformations without localization. The early buckling of the plastic stream is the reason for the reduced technological plasticity of the alloys, leading to cracking during stretching and precipitousness during broaching. In the practice of product control, the main reasons for the formation of cracks during cold plastic deformation of a flexible plate are considered to be the incorrectly chosen bend radius and insufficient plasticity of the metal [1].

It was experimentally shown [2] that, due to low plasticity in the thickness of the rolled sheet, its plastic deformation can cause a "splitting" - a discontinuity of the metal - even before the formation of the main crack. The process sensitivity of splitting formation to such factors as texture and the degree of local plastic deformation causes serious difficulties in obtaining quality structural elements. Theoretical studies [3] found that the viscous stretching during tension is preceded by the formation of the neck and the beginning of crack growth in it, that leads to the rupture of the sample. This corresponds to the values of uniform $\delta_{\mathrm{p}}$ and concentrated $\delta_{\mathrm{s}}$ deformations, that help to determine the technological parameters of bending - the bending radii. The ultimate strain state of the material in the process of bending the preform preceding its destruction is estimated [1] by the minimum bending radius $r_{\min }$. The permissible bending radius $r_{\text {per }}$ established by the standard [4] shows the geometry of the concave surface of the angle and is ensured by the tool dimensions. In the process of forming a part from a thick sheet, the bend radius should not exceed the value of the minimum radius at which the material fractures on the convex surface of the sheet.

a)
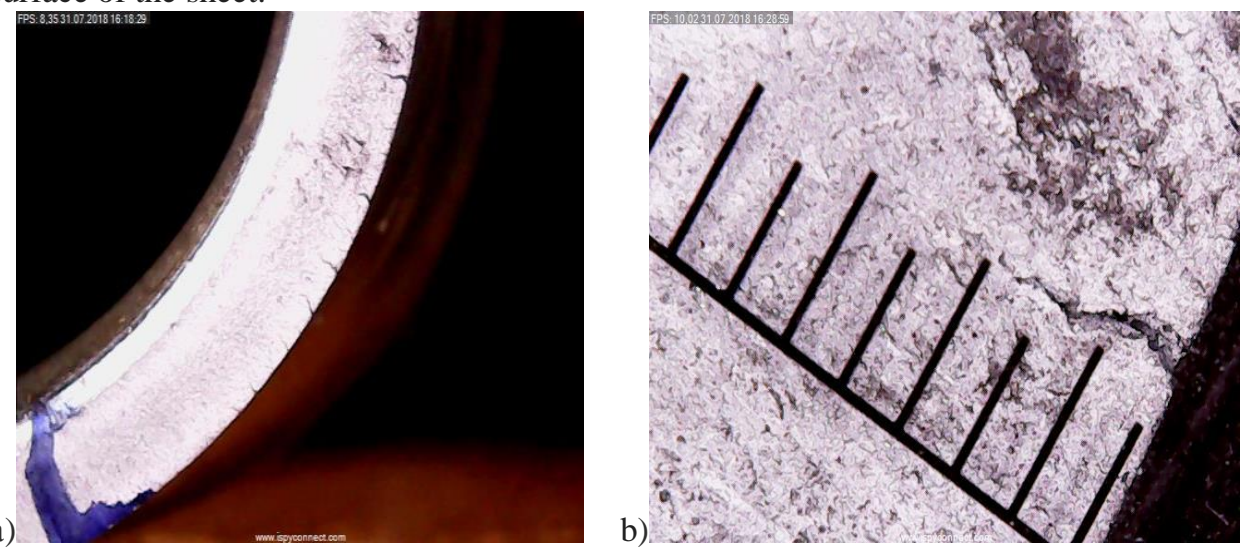

Fig. 1. Results of visual inspection: a) location of cracks on the convex surface of the fold; b) maximum dimensions of defects: length $-3.2 \mathrm{~mm}$, crack width $-0.2 \mathrm{~mm}$.

\section{Contents of the research}

Structural size control, chemical analysis of the steel, metallographic, electron microscopic studies and extended mechanical tests with the determination of $\sigma_{\mathrm{t}}, \sigma_{\mathrm{B}}, \sigma_{\mathrm{T}} / \sigma_{\mathrm{B}},\left(\delta_{5}\right) \psi, \mathrm{KCV}$ and KCU on samples cut along and across the edge of the detail bend were carried out to determine the causes of the cracks formation during the shaping of the steel plate. The presence of surface defects (cracks) of the metal found on the outer surface of the bending of the plate is confirmed by naked eye and 10 times magnifying lens inspection of the cross-section of the parts sample (Figure 1). Cracks of different lengths and opening widths $\left(\mathrm{h}_{\max }=3.2 \mathrm{~mm}, \mathrm{a}=0.2 \mathrm{~mm}\right)$ in the form of tortuous thin wedges directed from the edge to 
the depth of the sheet, are separated from each other at a distance of about $2 \mathrm{~mm}$, presumably with a step of the layers of the structure. The depth of the fixed cracks is not more than $0.2 \mathrm{~mm}$. Cracks were not found in the middle of the section.

In the case under consideration, the technical requirements [4] establish that for rolled steel from steels with a standard yield strength up to $275 \mathrm{MPa}$, the permissible minimum bending radius $r_{\text {per }}$ is $25 \mathrm{~mm}$, and for the parts used in the structures of Group I, the radius should be increased by 1.3 times (up to $32,5 \mathrm{~mm}$ ).

For the installation connection in question, the verification of the geometric shape and dimensions of the mounting connection showed that in the investigated sample of $90^{\circ}$ thick plates with a thickness of $\mathrm{s}=8 \mathrm{~mm}$, the height of the short leg straight part ( $\mathrm{h}=50 \geq 2 \mathrm{~s})$ and the inner bending radius $\left(r=33>r_{\text {per }}=32.5\right.$ and $\left.r_{p e r}=25\right)$ are not undervalued. Therefore, we came to the conclusion that the factory radius of the fold cannot be the cause of the cracks appearance on the convex surface of the curved plate.

According to the spectrometric control of the ARL easy Spark (GOST 22536.0-87) optical emission spectrometer, it was established that the chemical composition of the used steel $(0.17 \ldots 0.21 \% \mathrm{C}, 0.43 \% \mathrm{Mn}, 0.16 \% \mathrm{Si}, 0.010 \% \mathrm{~S}, 0,020 \% \mathrm{P})$ meets the requirements of GOST27772-2015 for sheet rolled products of class C245 and grade St3sp (GOST 3802005). Weak coloring of the points of the "sulfur fingerprint" serves as an additional confirmation of the sulfur harmful impurities low content in the steel and therefore high quality of steel.

The structure of the non-etched section examined in the light microscope shows the uniform distribution of nonmetallic inclusions (in the form of oxides and nitrides), as well as large inclusions of a streamlined shape (Figure 2a). The image of the etched section is dominated by light grains of ferrite and small uniformly distributed black grains of perlite, characteristic of the structure of hot-rolled steel of low-carbon steel (Fig. 2b). The structure with "pearlitic banding" along the rolling is not visible. Nonmetallic inclusions are located along the boundaries of the actual austenite grain.

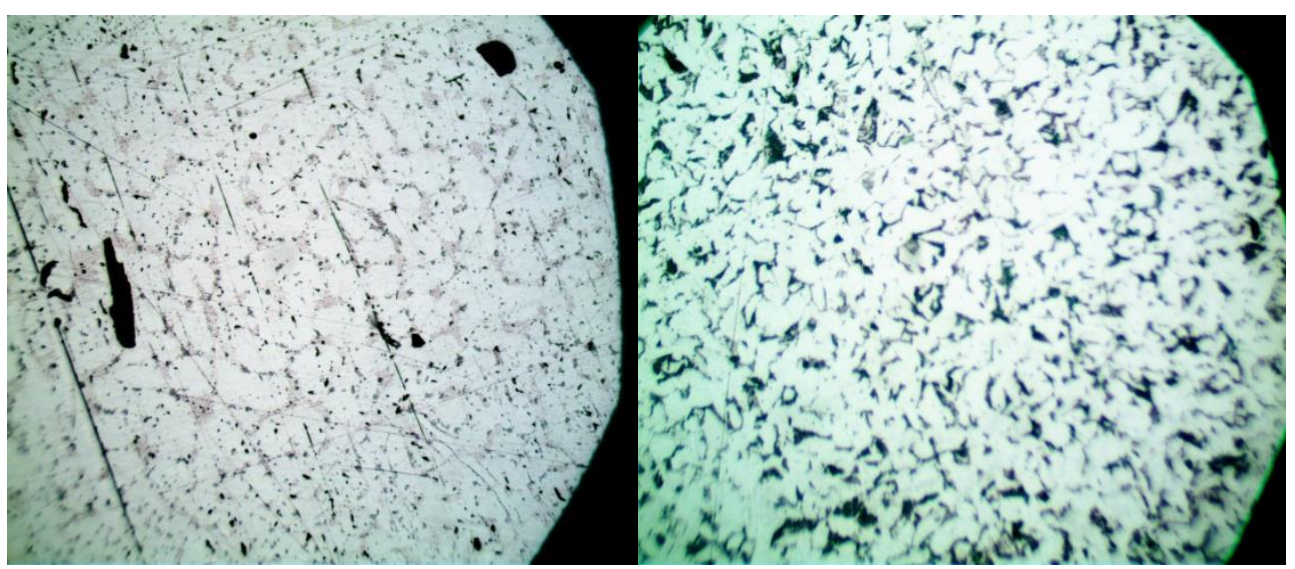

Fig. 2. The microstructure of steel (x 100) along the rolled products: a) on the non - etched section shows the contamination of rolled non-metallic inclusions, $\mathrm{b}$ ) on the etched section shows the finegrained structure of steel: dark areas-perlite $(15 \ldots 20 \%)$, light grains-ferrite $(80 \ldots 85 \%)$.

The study of the heterogeneity of the steel structure by nonmetallic inclusions, performed in scanning and spectrometry modes on the Quanta 200 electron microscope, allowed to determine (Fig. 3) a streamlined outline of gas pores, empty or filled with slag of the following elemental composition (weight \%): 29,47 C; 36,90 O; 21,52 Ca; 1,50 Si; 4,43 Al. 

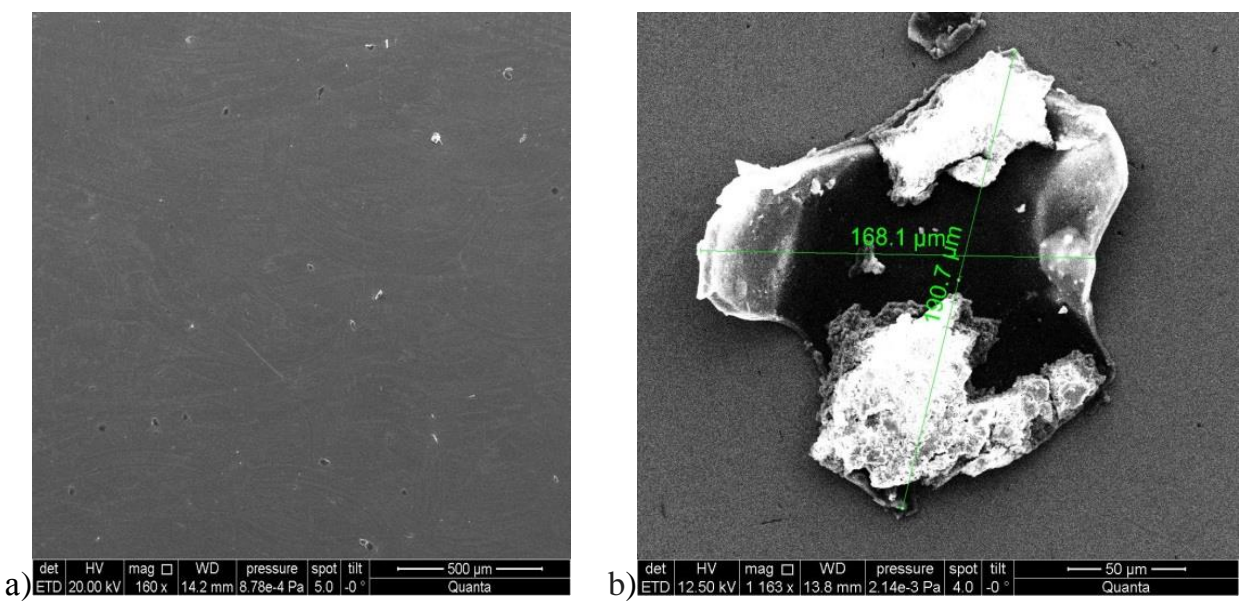

Fig. 3. Distribution (a), shape and dimensions of non-metallic inclusions (b) in steel. Scanning electron microscope, magnification: a-160x, b-1163x.

When explaining the mechanism of steel fracture by the formation of "splitting" we can suggest [2] the existence of weak surfaces parallel to the plane of rolling and due to the fibrous macrostructure.

The steel resistance to deformation and fracture on the samples cut along and across the bend line of the assembly connection are presented in table 1.

Table 1. Characteristics of strength, ductility and toughness of steel according to the test results.

\begin{tabular}{|c|c|c|c|c|c|c|c|c|}
\hline \multirow{2}{*}{$\begin{array}{l}\text { No. } \\
\text { sample's }\end{array}$} & \multirow[t]{2}{*}{ Direction* } & $\sigma_{t}$ & $\sigma_{\mathrm{V}}$ & \multirow[b]{2}{*}{$\sigma_{\mathrm{t} /} \sigma_{\mathrm{v}}$} & $\psi$ & $\delta_{5}$ & $K C V$ & $K C U$ \\
\hline & & \multicolumn{2}{|c|}{$\mathrm{MPa}$} & & \multicolumn{2}{|c|}{$\%$} & \multicolumn{2}{|c|}{$\mathrm{J} / \mathrm{cm}^{2}$} \\
\hline 1 & \multirow{4}{*}{$\begin{array}{l}\text { Along fold } \\
\text { lines and } \\
\text { fiber rental }\end{array}$} & 297,5 & 448,3 & 0,66 & 69,7 & 35,6 & 91,8 & $96.0,3$ \\
\hline \multirow[t]{3}{*}{2} & & 311,4 & 457,4 & 0,68 & 66,3 & 33,6 & 89,7 & 104,4 \\
\hline & & \multicolumn{7}{|c|}{ Average value } \\
\hline & & 304,4 & 452,9 & 0,67 & 68,0 & 34,6 & 90,7 & 100,2 \\
\hline 3 & across the & 314,5 & 456,8 & 0,69 & 62,6 & 34,7 & 208,3 & 198,3 \\
\hline \multirow[t]{3}{*}{4} & bending line & 329,8 & 462,4 & 0,71 & 61,4 & 34,6 & 206,9 & 174,9 \\
\hline & and rolled & \multicolumn{7}{|c|}{ Average value } \\
\hline & fibers & 322,2 & 452,6 & $\mathbf{0 , 7 0}$ & 62,0 & 34,6 & 207,6 & 186,6 \\
\hline
\end{tabular}

The tests showed that the bent sheet of the mounting connection in both rolling directions has:

- the same values of the relative elongation $\delta_{5}$, and the ultimate tensile strength $\sigma_{\mathrm{v}}$,

- the same deformation hardening $\left(\sigma_{\mathrm{t} /} \sigma_{\mathrm{v}}\right)$,

- anisotropy of properties along the yield point $\left(\sigma_{t}\right)$ relative narrowing $(\psi)$ and toughness (KCV, KCU).

From the obtained data it follows that the control indicators of the mechanical properties $\left(\sigma_{\mathrm{t}}, \sigma_{\mathrm{v}}, \delta_{5}\right)$ incorporated in the standard [4], do not allow the consumer to detect the difference in workability of the workpiece cut along or across the rolling. The manufacturer does not take into account the position of the bending line of the part relative to the 
direction of the rolled structures fibers. To determine the reasons for the appearance of cracks, it is necessary to evaluate more informative characteristics such as relative narrowing and impact strength, taking into account the plasticity of the material over the thickness of the sheet.

Figure 4 shows a characteristic view of the fracture along (a) and across (b) the bending line of the plate. The surface of failure (b) differs from the fracture of longitudinal specimens by a set of heterogeneous splittings.
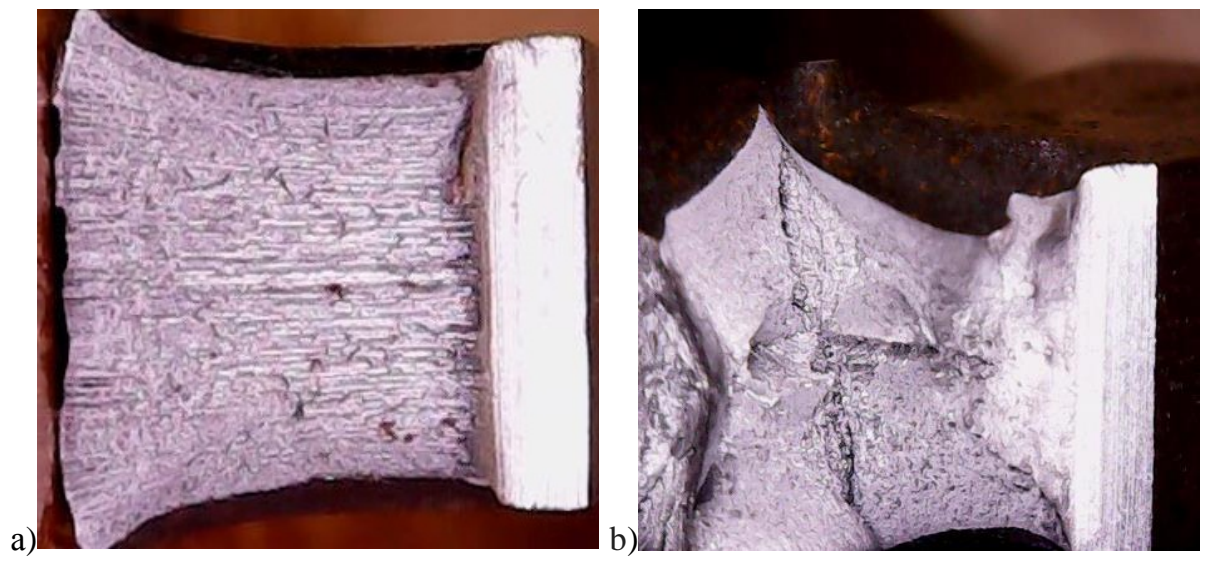

Fig. 4. Fibrous (a) and split (b) broken impact specimens.

Therefore, the correct molding technology must take into account the position of the bending line relative to the fibers of the rolled preform, which changes the requirements for the minimum folding radius of the sheet. If the fold line passes along the rolled fibers, according to [5], the danger of cracking during bending of annealed steel 20 and St3 appears already at $r_{\min }=0,5 \mathrm{~s}$; and if the bending is across the fibers, then at 5 times smaller radius $r_{\min }=0,1 \mathrm{~s}$. Bending along the fibers splits the ends of the fibrous composition for those nonmetallic inclusions that are formed during the melting of steel (Fig. 3). It is indicative that hardening increases the resistance and when the cold-rolled sheet is deformed, the minimum bending radius can be increased by $2 \ldots 5$ times.

To assess the processability of the material, the values of the relative minimum and permissible bend radii $\mathrm{r} / \mathrm{s}$ for the controlled part were calculated [1]. The calculation model made it possible to determine the dimensions of the bend in the parameter "e", which takes into account the ratio of the uniform $\delta_{\mathrm{p}}$ and the concentrated elongation $\delta_{\mathrm{c}}$ of steel $\mathrm{e}=$ $\delta_{\mathrm{c}} / \delta_{\mathrm{p}}$ both along and across the fibers. In this case, the uniform $\left(\delta_{\mathrm{p}}\right)$ and concentrated elongations $\left(\delta_{\mathrm{c}}\right)$ were calculated based on the equation of relative strength-plastic parameters [4] obtained by testing the above samples with uniaxial tension:

$$
\sigma_{\mathrm{T}} / \sigma_{\mathrm{B}}+\delta / \psi=\mathrm{C}=\left[\left(1+\delta_{\mathrm{c}}\right) /\left(1+\delta_{\mathrm{p}}\right)\right]^{1 / \psi},
$$

Under the condition of non-additivity of the elongation index $\delta=\left(\delta_{\mathrm{p}}+\delta_{\mathrm{c}}+\delta_{\mathrm{p}} \cdot \delta_{\mathrm{c}}\right)$ the expressions for its components have the form

$$
\begin{gathered}
\delta_{\mathrm{p}}=\left[(1+\delta) / \mathrm{C}^{\psi}\right]^{0,5}-1, \\
\delta_{\mathrm{c}}=\left(\delta-\delta_{\mathrm{p}}\right) /\left(1+\delta_{\mathrm{p}}\right),
\end{gathered}
$$

Table 2 presents the calculated indicators of manufacturability of the steel billet used such as the minimum and permissible bend radii $\left(r_{\min }, r_{\text {per }}\right)$ of sheet thickness (s) equal to $8 \mathrm{~mm}$. At the minimum radius, material fractures along the convex bending surface, with a permissible value of the bend radius - cracks are not allowed. 
Table 2. Indicators of manufacturability of the mounting connection material

\begin{tabular}{|c|c|c|c|c|c|c|c|c|}
\hline \multirow[t]{2}{*}{ No. } & \multirow{2}{*}{$\begin{array}{l}\text { The } \\
\text { direction of } \\
\text { the bending } \\
\text { line* }\end{array}$} & $\delta$ & $\delta_{\mathrm{c}}$ & \multirow{2}{*}{$\begin{array}{l}\mathrm{e}= \\
\delta_{\mathrm{c}} / \delta_{\mathrm{p}}\end{array}$} & \multicolumn{2}{|r|}{$\mathrm{R} / \mathrm{s}$} & \multicolumn{2}{|r|}{$\mathrm{r}, \mathrm{mm}$} \\
\hline & & \multicolumn{2}{|l|}{$\%$} & & $\min$ & permissible & $\min$ & permissible \\
\hline 1 & \multirow{2}{*}{$\begin{array}{l}\text { along the } \\
\text { rolled } \\
\text { fibers }\end{array}$} & 10,0 & 23,3 & 2,3 & 2,30 & 2,80 & 18,4 & 22,4 \\
\hline 2 & & 9,0 & 22,6 & 2,5 & 2,25 & 2,75 & 18,0 & 22,0 \\
\hline 3 & \multirow{2}{*}{$\begin{array}{l}\text { across the } \\
\text { rolled } \\
\text { fibers }\end{array}$} & 8,0 & 24,8 & 3,1 & 1,86 & 2,36 & 14,9 & 18,9 \\
\hline 4 & & 8,0 & 24,6 & 3,1 & 1,86 & 2,36 & 14,9 & 18,9 \\
\hline
\end{tabular}

The calculations show that the steel rolling used for making the assembly link allows even smaller bend radii than provided for by the technical requirements $\left(r_{\text {per }}=25 \mathrm{~mm}\right)$ [2].

Moreover, the minimum bending radius of the plate can be reduced if the bending line of the plate is positioned across the rolled fibers, and the long side of the billet is along the fibers.

\section{Conclusions}

Thus, the study and comprehensive analysis of the composition, structure and properties of the billet material showed that the cracks formation on the outer surface of the product was due to the fibrous structure of hot-rolled plate. To reduce the risk of installation connection fracture, it is necessary to revise the technological process for the production of the part. When performing the cutting operation of the sheet metal intended for the bending operation, the long side of the plate $(210 \mathrm{~mm})$ should be positioned along the direction of the structure fibers. During the bending operation, the folding edge of the sheet must be executed across the rolled fiber. For steels that are prone to splitting along the fibers of the structure, correct cutting of the sheet will prevent the formation of cracks along the stretched bending surface and fatigue failure during welding and operations of the assembly line.

All tests were carried out using research equipment of The Head Regional Shared Research Facilities of the Moscow State University of Civil Engineering (RFMEFI59317X0006).

\section{Reference}

1. Technological design of the product: Handbook / Y.D. Amirov, T.K. Alferov, P.N. Volkov et al., 2nd ed., Moscow: Mashinostroenie, 1990.-768p.

2. Gulyaev A.P. Features of the destruction of steel controlled rolling. - M and TOM, 1982, No.5, p.24 ... 26.

3. Janinier J.M. Calculation of the forming limit curve at fracture // J. of Material Science.1983.Vol / 18.36.P / 1794-1802.

4. SP53-101-98 "Manufacturing and quality control of steel building structures".

5. A quick reference metal worker / Under the general. Ed. P.N. Orlova, E.A. Skorokhodova -3-ed-M .: Mechanical Engineering, 1987.- 960s.

6. Gustov D.Yu., Gustov Yu.I. To the development of scientific foundations of building metallurgy. // Dokl. X Russian-Polish seminar "Theoretical Foundations of Construction". Warsaw, Moscow: Izd. ASV, 2001.- p.307-314. 